\title{
A atuação dos indígenas na História do Brasil: revisões historiográficas ${ }^{1}$
}

Indigenous Protagonism and Historical Reviews in Brazil

Maria Regina Celestino de Almeida*

Resumo

Para discutir a importância de incorporar os índios na História do Brasil como protagonistas, apresento uma reflexão sobre algumas mudanças historiográficas resultantes dessa incorporação, apontando a relevância acadêmica, social e política dessa prática. A inclusão dos índios em nossa história na condição de sujeitos tem propiciado novas interpretações sobre vários temas. Este artigo aborda alguns deles, priorizando minha pesquisa sobre os índios no Rio de Janeiro, em perspectiva comparativa com outras regiões do Brasil. Lembrando que a história indígena articula-se com as histórias colonial e nacional, o texto enfatiza a importância de estreitar diálogos entre os especialistas para compreensões mais complexas dos processos históricos. Do ponto de vista político e social, as novas interpretações históricas sobre os índios cumprem o papel essencial de desconstruir ideias preconceituosas e discriminatórias.

Palavras-chave: protagonismo indígena; historiografia; história indígena.

\section{Abstract}

To discuss the importance of incorporating the Indians in the History of Brazil as protagonists, I present a reflection on some historiographical changes resulting from such incorporation, pointing out the academic, social and political relevance of this practice. The inclusion of the Indigenous agency in our history has provided new interpretations on various themes. This article addresses some of them, focusing primarily on my research on the Indians in Rio de Janeiro, in a comparative perspective with other regions of Brazil. Considering that the Indian history is articulated with colonial and national histories, the text emphasizes the importance of increasing dialogues among specialists for more complex understandings of historical processes. From the political and social point of view, these new historical interpretations have an essential role of deconstructing prejudiced and discriminatory ideas against the Indians.

Keywords: indigenous protagonism; historiography; indigenous History.

\footnotetext{
* Programa de Pós-Graduação em História (PPGH), Universidade Federal Fluminense, Campus do Gragoatá. Niterói, RJ, Brasil. mreginacelestino@gmail.com
} 
Quando os índios forem considerados sujeitos históricos e os múltiplos processos de interação entre suas sociedades e as populações que surgiram com a colonização europeia forem recuperados, "páginas inteiras da história do país serão reescritas; e ao futuro dos índios reservar-se-á um espaço mais equilibrado e, quem sabe, otimista" (Monteiro, 1995, p.228). Com essas palavras, John Monteiro finalizava, em 1995, um capítulo sobre os desafios da História indígena no Brasil e conclamava os historiadores a enfrentarem a tarefa.

Vinte anos depois, até onde caminhamos? A questão proposta por este Dossiê aponta para os avanços das pesquisas no campo da história indígena e convida para a importante reflexão já colocada por Monteiro no artigo citado. Refiro-me às indispensáveis articulações entre as histórias dos índios, as histórias regionais e, em perspectiva mais ampla, a história do Brasil. Afinal, como afirmou Hill (1996), as histórias indígenas se entrelaçaram com as histórias dos europeus desde que eles chegaram à América. Para a compreensão dos complexos processos históricos de formação e desenvolvimento das sociedades americanas é imprescindível levarmos em conta a presença e o protagonismo significativos dos inúmeros e distintos povos nativos do continente, que foram todos chamados índios.

Desde a década de 1970, a história do Brasil tem se renovado, com novas abordagens sobre vários temas. Novas perspectivas teóricas e conceituais somadas à incorporação cada vez maior de diversos tipos de fontes e à contínua e crescente interlocução dos historiadores com os demais especialistas das ciências sociais têm propiciado leituras inovadoras sobre o nosso passado. A inclusão de novos atores e a preocupação em identificar suas ações, escolhas e interesses na dinâmica de suas trajetórias desconstroem visões generalizantes e simplistas, abrindo um leque de novas possibilidades interpretativas sobre os mais variados processos históricos (Cardoso; Vainfas, 1997; 2012). Entre esses atores incluem-se, cada vez mais, os povos indígenas, cujo protagonismo, no entanto, passou a ser mais valorizado pelos historiadores apenas na década de 1990 (Monteiro, 2001). Desde então, o que tem mudado em nossa história? Qual a importância de incorporá-los como sujeitos? Embora ainda lentas, as mudanças, além de significativas, são de importância fundamental do ponto de vista acadêmico, social e político, tanto para os povos indígenas quanto para os não indígenas.

\section{O LUGAR DOS ÍNDiOS NA HistóRIA: ALguMAS REFlEXões}

Os índios sempre estiveram na história do Brasil, porém, grosso modo, como força de trabalho ou como rebeldes que acabavam vencidos, dominados, 
escravizados, aculturados ou mortos. Suas ações não eram, absolutamente, consideradas relevantes para a compreensão dos rumos da história. Essas concepções, predominantes por tanto tempo em nossa historiografia, já não se sustentam. Inúmeras pesquisas não deixam dúvida sobre o fato de que as ações e as escolhas indígenas deram limites e possibilidades aos processos de conquista e colonização das diferentes regiões do Brasil (Almeida, 2010).

Cabe, então, perguntar como era (e ainda é) possível explicar tais processos sem levar em conta o protagonismo indígena. Como entendíamos a vitória e o domínio dos portugueses sobre milhares de povos guerreiros? Como explicávamos o sucesso de apenas duas das várias capitanias hereditárias, quando as outras soçobravam diante dos ataques indígenas? Como podiam alguns degredados ocupar postos chaves nas sociedades nativas, que lhes permitiram fornecer o imprescindível auxílio aos portugueses? Como conseguiam dois missionários controlar centenas de índios nas aldeias coloniais? Como explicávamos essas e tantas outras questões de nossa história sem considerar o protagonismo indígena? Como e por que vários povos considerados extintos e, por longo tempo, excluídos da História do Brasil estão, hoje, ressurgindo no cenário político e acadêmico do país?

A pouca importância dada às atuações dos índios e o apagamento de suas identidades étnicas construíram-se pari passu com a supervalorização do desempenho dos colonizadores em narrativas eurocêntricas e preconceituosas que davam conta de responder às questões citadas. Heróis ou vilões, os poderosos portugueses teriam sido capazes de dominar milhares de povos guerreiros, catequizá-los e discipliná-los, fazendo-os trabalhar e defender a terra como fiéis e submissos servidores do rei. Com leis que oscilavam entre o apoio a práticas de violência e de proteção aos índios, os portugueses e, posteriormente, os brasileiros teriam conseguido vencer, civilizar e/ou manipular inúmeros povos em proveito próprio, submetendo-os completamente, até fazê-los desaparecer sem deixar vestígios.

Essa "crônica da extinção" que, como afirmou Monteiro (1995), por tanto tempo caracterizou as abordagens históricas sobre os índios no Brasil era, de fato, coerente com as perspectivas historiográficas e as políticas indigenistas vigentes no século XIX e em boa parte do XX (Guimarães, 1988; Monteiro, 2001; Kodama, 2009; Almeida, 2010). As narrativas de conquista e colonização enalteciam a ação heroica e desbravadora dos portugueses, enquanto os índios pareciam ser facilmente vencidos, catequizados e transformados por eles. Nos anos 1960 e 1970, uma historiografia de base marxista, propulsora da chamada história dos vencidos, criticava essas abordagens com denúncias sobre as 
atrocidades cometidas contra os índios. Desconstruíam o caráter heroico dos nossos colonizadores, porém mantinham a perspectiva anterior de supervalorização de seu desempenho, na medida em que consideravam os índios como vítimas incapazes de agir diante da violência de um sistema no qual não tinham outra alternativa a não ser a fuga, a morte pela rebeldia ou a submissão aos dominadores. A mensagem subjacente em narrativas como essas, nas quais um grupo, na condição de herói ou de vilão, vencia, dominava e anulava o outro enquanto agente social, parece bem clara na afirmação da superioridade de uns sobre os outros.

Predominantes em nossa historiografia e continuamente alimentadas pela mídia e pelas narrativas históricas em escolas, colégios e universidades, essas ideias foram facilmente incorporadas no imaginário da população brasileira, com imensos prejuízos para todos, mas principalmente para os índios. Duplamente violentados, como afirmou Carneiro da Cunha (1992), pois além de terem enfrentado as trágicas consequências dos processos históricos vivenciados, sofreram e ainda sofrem os efeitos da história disciplina, na qual figuram em papéis secundários e depreciativos, entre as posições de vítimas passivas, bons selvagens ou bárbaros sanguinários. Historicídio, nas palavras de Hill (1996), que contribuiu para reforçar em nossa sociedade ideias preconceituosas e estereotipadas sobre eles.

Ainda muito presentes no senso comum da população brasileira, essas ideias, além de extremamente danosas à autoestima dos índios, reforçam entre os não indígenas sentimentos preconceituosos e discriminatórios que resultam em atitudes de intolerância e violência contra eles. Desconstruí-las é tarefa essencial dos historiadores. É o que tem sido feito nas últimas décadas, com resultados ainda bastante acanhados em face das imensas dificuldades em desconstruir concepções tão profundamente arraigadas.

Porém, não se trata apenas de repensar a trajetória dos povos indígenas em situações de contato, como tem sido feito por inúmeras pesquisas em diferentes regiões do Brasil. O mais difícil e fundamental é incorporar essas pesquisas para repensar a própria história do Brasil, como alertava Monteiro em 1995. A proposta deste Dossiê é um passo importante nessa direção. Sabemos que a realidade, de fato, não se divide, e a compartimentalização do saber histórico em vários campos de estudo atende à necessidade de especialização, diante da complexidade dos objetos de análise que exigem recortes cada vez mais estreitos do ponto vista temático, temporal e espacial. Daí a importância do diálogo contínuo entre os especialistas de forma a superar interpretações estanques que limitam as possibilidades de análise. Se os avanços 
historiográficos nas diversas áreas da história têm contribuído, de forma essencial, para repensarmos as histórias dos índios, estas últimas vão, cada vez mais, propiciando novas compreensões sobre diferentes temas. Alguns deles têm sido trabalhados por historiadores em diferentes regiões do Brasil fundamentando novas interpretações sobre nossa história. Para responder à questão colocada no Dossiê, refletindo sobre o que muda em nossa história com a incorporação dos índios como protagonistas, vou abordar alguns deles com base em minha própria experiência de pesquisa sobre os índios e as aldeias do Rio de Janeiro.

\section{Protagonismo indígena Na História do RIO DE JANEIRO: NOVAS INTERPRETAÇÕES}

O olhar antropológico sobre as fontes históricas nos leva a desvendar os diferentes significados que os mesmos objetos, comportamentos e acordos podem ter para grupos e indivíduos social e etnicamente distintos (Mintz, 2010). Analisar a documentação, focando os índios e os significados próprios por eles atribuídos aos novos artefatos, relacionamentos, condutas e instituições que passavam a fazer parte de seu cotidiano pós-contato, nos leva a compreender os processos de conquista e ocupação da terra de forma mais ampla e complexa. Sem desconsiderar o tamanho da violência contra os índios e as condições desiguais de negociação entre eles e os europeus, podemos observar que, apesar de restritas, suas atuações impuseram uma série de limites aos colonizadores. As narrativas históricas, sem dúvida, se alteram quando incorporamos os índios na condição de protagonistas, como pretendo demonstrar abordando alguns temas sobre os quais tenho trabalhado.

\section{GUERRAS INDÍGENAS E GUERRAS COLONIAIS}

As narrativas históricas sobre a conquista do Rio de Janeiro sempre incluíram os índios. Afinal, o território foi conquistado mediante uma guerra violentíssima na qual participaram todos os segmentos sociais da colônia: autoridades, missionários, colonos e povos nativos de diferentes etnias. Ao focar o olhar sobre estes últimos, procurando compreender suas relações com os europeus a partir de seus próprios interesses, descortinamos um panorama complexo e dinâmico sobre as guerras e as ações dos personagens envolvidos. 
A identificação dos diferentes grupos étnicos que responderam ao contato com os europeus de formas distintas desmonta esquemas simplistas que apresentavam os combatentes em blocos monolíticos e cristalizados nos papéis de aliados ou de inimigos. No Rio de Janeiro, ao invés de franceses e tamoios de um lado e portugueses e temiminós de outro, percebemos uma complicada rede de interações na qual circulavam os diferentes subgrupos tupis, em um vaivém de acordos e disputas entre si e com os europeus. Mudavam de lado frequentemente, conforme as circunstâncias e seus interesses, que se modificavam com as experiências do contato (Almeida, 2003).

Além disso, percebemos que os etnônimos utilizados pelos portugueses para classificar os vários povos nativos comportam grande dose de invenção (Monteiro, 2001). Eram, afinal, classificados com base nos interesses e em compreensões bem equivocadas dos portugueses sobre suas línguas e características socioculturais, o que levou à criação de inúmeras novas etnias. Acredito ter sido esse o caso dos temiminós, pois vários indícios sugerem que eles eram, provavelmente, um grupo dissidente dos tamoios que, em conjuntura de guerra, acabou optando pela aliança com os portugueses. Entre embates e acordos, acabaram assumindo a identidade sugerida pelos novos aliados e, com certeza, mais condizente com seus interesses naquele momento: tornaram-se os fiéis e valorosos temiminós que, liderados por Arariboia, contribuíram para a conquista da Guanabara, o que lhes valeu certos ganhos. Não tenho dúvida de que participaram dessa guerra movidos por interesses próprios (Almeida, 2003).

Situações similares ocorreram em outras regiões do Brasil, como têm demonstrado inúmeros estudos localizados. Os processos de etnificação - isto é, as mudanças culturais e identitárias impostas aos índios em situações de contato - têm sido analisados de forma articulada aos processos de etnogênese. Estes são os movimentos dos próprios povos nativos que, em resposta às mais variadas situações de desafio e violência, reelaboram práticas e relações culturais, políticas, econômicas e sociais, construindo, para si e para os outros, novas formas de identificação (Boccara, 2001; Barth, 2000; Thompson, 1987).

Considerando que os índios agiam movidos por interesses ligados às dinâmicas de suas organizações socioculturais, é essencial conhecê-las para compreender melhor suas relações interétnicas. Os estudos etnológicos sobre os tupis que, divididos em vários subgrupos, predominavam na costa brasílica, conduzem a novas compreensões sobre suas relações de contato no Rio de Janeiro e nas demais capitanias litorâneas. Uma de suas características mais marcantes e fundamentais para essa compreensão era a extrema abertura às relações de alteridade que davam sentido às suas sociedades e se faziam, 
basicamente, mediante trocas, casamentos e guerras com grupos rivais e aliados (Fernandes, 1989; Viveiros de Castro, 1992; Fausto, 2000). Daí a facilidade com que inseriram os europeus em suas relações intertribais, concedendo-lhes presentes e mulheres e integrando-os em suas guerras, como aliados ou inimigos. Isso nos permite entender a inserção de João Ramalho entre os Tupiniquins de São Paulo e de Caramuru entre os Tupinambás na Bahia, degredados que se casaram com as filhas de grandes chefes e alcançaram postos de chefia e prestígio nos grupos que os acolheram (Monteiro, 1994; Almeida, 2003). Ambos, evidentemente, incorporaram os costumes indígenas e atuaram conforme suas normas, pois, caso contrário, teriam sido mortos como tantos outros degredados.

Essas abordagens nos levam a identificar os limites das ações dos europeus e suas necessidades em negociar e abrir mão de exigências para conseguir o imprescindível apoio dos nativos. Se Alexander Marchant (1980) e John Hemming (2007) já haviam, há décadas, evidenciado a violência das guerras contra os índios, desconstruindo a imagem de conquista relativamente pacífica do território português na América, as pesquisas atuais demonstram como as escolhas e ações indígenas foram decisivas para vitórias ou derrotas, embora eles próprios tenham sido sempre os maiores prejudicados. A maioria das capitanias hereditárias fracassou, em grande parte, por causa de ataques indígenas, e as duas que mais prosperaram - São Vicente e Pernambuco - foram aquelas cujos donatários puderam contar com o inestimável apoio de chefes nativos, com os quais estabeleceram estreitos laços de aliança (Monteiro, 1994; Barbosa, 2007).

Sob essa perspectiva, ao invés de heróis portugueses derrotando indios selvagens com o apoio de indios fiéis e submissos que teriam se convertido completamente aos valores socioculturais portugueses, deparamos com grupos étnicos e sociais distintos que lutavam e negociavam, cada qual procurando fazer valer seus interesses. Os índios, por sua vez, deixam de ser vistos como tolos e manipulados, pois suas ações passam a ser entendidas como fruto de escolhas próprias condizentes com as lógicas de suas sociedades e com as possibilidades disponíveis. Escolhas limitadas, sem dúvida, pois as relações eram assimétricas e ocorriam em meio a um cenário caótico de extrema violência.

\section{ELITES COLONIAIS E ELITES INDÍGENAS EM TEMPOS DE GUERRA}

O protagonismo dos índios nas guerras e nos disputados acordos que estabeleciam com os europeus tem propiciado novas compreensões sobre a 
formação das elites coloniais na América Portuguesa. Afinal, se as guerras a serviço do rei constituíam uma das principais possibilidades de ascensão social na colônia e as alianças com os índios eram imprescindíveis para vencê-las, é lícito supor que suas ações e escolhas influenciavam as possibilidades de enobrecimento de inúmeros portugueses e luso-brasileiros.

As solicitações de mercês, grosso modo, faziam referências às atividades guerreiras em defesa dos interesses do rei, o qual recompensava seus súditos distribuindo-lhes benefícios, como demonstrou João Fragoso ao tratar da formação das elites na capitania do Rio de Janeiro (Fragoso, 1995). De acordo com o autor, a fortuna, o poder e o prestígio eram alcançados, em grande parte, graças aos bons serviços prestados nas guerras de conquista. Além de escravos indígenas, obtidos pela legítima escravização dos vencidos garantida na lei, os conquistadores tinham a possibilidade de receber da Coroa títulos, cargos e patentes que lhes conferiam posição privilegiada na colônia. Situação semelhante foi observada por Rafael Rocha (2013) que, analisando a formação das elites no Maranhão no século XVII, demonstrou como cargos e patentes eram distribuídos, preferencialmente, aos súditos bem relacionados com poderosos chefes indígenas que lhes possibilitavam a vitória nas guerras de conquista. $\mathrm{Na}$ capitania de São Vicente, particularmente na vila de São Paulo, as elites coloniais se formaram pela miscigenação com os povos indígenas, como tão bem demonstra Silvana de Godoy. Por meio de casamentos, formou-se ali, de acordo com a autora, uma elite indigenista bastante dependente dos povos indígenas, com os quais mantinha intensas e complexas relações que iam do parentesco e afeto à extrema violência (Godoy, 2017).

Essas e outras pesquisas apontam para o papel decisivo das ações e escolhas dos índios no processo de formação de elites coloniais, em conjunturas de guerra. Indispensáveis como aliados, eles mereciam especial atenção dos agentes locais e de autoridades civis e eclesiásticas (na colônia e na metrópole), todos cientes da importância de agradá-los. Os líderes indígenas, por sua vez, sabedores da importância do seu papel, negociavam suas alianças em troca de benefícios que iam além dos ganhos materiais. Suas importantes funções, principalmente nas guerras, abriam espaço para certa ascensão social que, embora limitada, foi por eles bastante valorizada.

Em diferentes tempos e espaços, chefes indígenas foram enaltecidos com nomes portugueses de prestígio e concessão de favores, cargos, patentes militares e até títulos de cavaleiros de ordens militares, aos quais não poderiam ter acesso em razão dos estatutos de limpeza de sangue (Mello, 1989). Contudo, os critérios de hierarquia social na colônia flexibilizavam-se conforme as 
especificidades locais, como demonstram as trajetórias de Arariboia e de outros líderes indígenas. A necessidade do rei e de autoridades coloniais em obter as alianças com os chefes nativos, somada ao gosto destes últimos em alcançar as honras anunciadas, incentivavam sua distribuição, o que gerou desacordos entre a Mesa de Consciência e Ordens e o rei. Sem abordar as complexas discussões sobre este tema, vale ressaltar as análises de Carvalho Júnior (2017) e Raminelli (2015) que demonstraram as estratégias das autoridades para condecorar os índios de forma limitada, sem romper as leis. Esses últimos souberam aceitar as limitações, utilizando os possíveis ganhos a seu modo. Fundamental nessas análises é perceber os significados próprios que os índios atribuíam aos seus ganhos e honrarias.

Sem desconsiderar os limites da mobilidade social permitida aos índios e os preconceitos e discriminações contra eles que não se apagavam com as nobilitações alcançadas e se mantiveram por todo o período colonial, é possível perceber a formação de uma elite indígena na colônia criada, principalmente, em conjunturas de guerra. Além disso, a nobreza da terra em São Paulo e, com certeza, em várias outras regiões constituiu-se mediante intensa miscigenação com os nativos. Práticas de enobrecimento de indígenas e não indígenas parecem, portanto, ter caminhado juntas no empreendimento da conquista e da colonização. Estudá-las de forma associada é um caminho que já vem sendo percorrido por alguns historiadores, cujas pesquisas apontam novas possibilidades interpretativas sobre o tema.

\section{Aldeias COlONiais: ReARTiCUlaÇões SOCIAIS, CULTURAIS E IDENTITÁRIAS}

A política de aldeamentos da Coroa Portuguesa, essencial para a ocupação do território na capitania do Rio de Janeiro, só foi possível pela negociação com os chefes indígenas. Cabe lembrar que, nos séculos XVI e XVII, a dependência dos portugueses em relação aos índios era imensa, e a construção do projeto de colonização dependia, em grande parte, das dinâmicas locais. Dinâmicas essas que incluem as ações dos povos subalternos, tais como indígenas, africanos e seus descendentes, como a história indígena e a história da escravidão estão revelando.

O próprio projeto jesuítico de catequese foi repensado a partir dos desafios locais (Castelnau-L'Estoile, 2006), dentre os quais destacam-se as reações dos índios à presença dos missionários em suas aldeias e, sobretudo, a 
intensificação das guerras indígenas em toda a costa brasileira. Da pregação itinerante passou-se à prática de deslocar os índios para aldeias construídas nas proximidades dos núcleos portugueses. As guerras coloniais, as guerras justas e as muitas expedições de apresamento de índios andavam pari passu com a política de aldeamentos, pois diminuíam as possibilidades de sobrevivência dos índios nos sertões e os levavam, grosso modo, a acordos com os portugueses para o ingresso nas aldeias.

Essenciais na política de colonização, as aldeias, estabelecidas com o acordo entre Coroa e Igreja, visavam não apenas cristianizar os índios, mas ressocializá-los, tornando-os súditos cristãos do rei, com vários papéis a cumprir na nova sociedade que se construía. As infindáveis leis sobre sua criação e funcionamento (Perrone-Moisés, 1992), bem como as inúmeras e variadas disputas em torno delas indicam, além de sua importância, as diferentes expectativas dos diversos atores (índios, missionários, autoridades, colonos etc.) em relação a elas. Embora as fontes sejam limitadas para identificarmos os interesses dos índios, seus acordos e reivindicações ao rei nos dão indícios sobre suas principais aspirações no ato de aldear-se: terra e proteção eram condições básicas nos acordos de paz. Diante das guerras, escravizações em massa e crescente redução de territórios livres e recursos naturais, as aldeias coloniais eram, para eles, o mal menor (Almeida, 2003).

Nas aldeias do Rio de Janeiro, como nas de várias outras regiões, os índios ressocializaram-se por meio de intenso processo de metamorfoses num cotidiano repleto de negociações, tensões e conflitos nos quais os jesuítas tiveram papel fundamental. Com o intuito de transformar e homogeneizar ensinaram-lhes novas práticas culturais e políticas habilmente utilizadas, por eles, em busca de possíveis ganhos que a condição de aldeados lhes propiciava. A evangelização dos índios e suas complexas relações com os missionários nas aldeias também têm merecido novas interpretações baseadas nas abordagens interdisciplinares. As concessões, tolerâncias e apropriações de elementos culturais indígenas por parte dos jesuítas em suas práticas de catequese e de gestão administrativa, tão evidentes na documentação do Rio de Janeiro e de várias outras regiões, explicam como dois missionários podiam controlar centenas ou até milhares de índios em suas aldeias. O catolicismo imposto aos índios já não é visto simplesmente como instrumento de dominação. Ao enfocar as próprias formas de compreensão e usos da religiosidade por parte dos conversos, as pesquisas atuais revelam novas compreensões sobre as relações com os missionários e as práticas de religiosidade na colônia (Pompa, 2003; Vainfas, 1995; Carvalho Júnior, 2017). A conversão lhes dava instrumentos para se 
adaptarem às sociedades envolventes e atuarem politicamente, solicitando mercês e contestando injustiças e situações indesejadas, conforme as regras portuguesas.

Os aldeados apropriaram-se da cultura política do Antigo Regime, baseada na troca de favores e serviços, num sistema de reciprocidade no qual os súditos serviam ao rei que, em seu papel de monarca justo e piedoso, os recompensava. Em suas petições, apresentavam-se com o nome de batismo cristão, a partir da aldeia na qual habitavam, enfatizando, em geral, os muitos serviços prestados ao rei que os faziam merecedores das solicitações reivindicadas. Rearticularam-se, portanto, social e culturalmente, entre si e com outros grupos, assumindo a nova identidade que lhes havia sido dada ou imposta pelos colonizadores: a de índios aldeados, súditos cristãos de Sua Majestade. Nessa condição, identificavam-se e eram identificados até o início do século XIX, quando ainda lutavam para garantir o mínimo de direitos que a legislação lhes permitia (Almeida, 2003).

\section{ESCRAVIDÃO E TRABALHO INDÍGENA}

Desde as pesquisas de Stuart Schwartz (1988) na Bahia e de John Monteiro (1994) em São Paulo, o equivocado pressuposto de que a mão de obra indígena teria sido pouco utilizada na agricultura já não se sustenta. No Rio de Janeiro, do século XVI ao XIX, os índios, na condição de escravos ou aldeados, integraram a força de trabalho da região. Essa integração variou, ao longo do tempo, quanto às diferentes atividades exercidas e, principalmente, quanto à sua intensidade.

Apesar da escassez de fontes para se identificar os escravos índios dadas as restrições legislativas, há claros indícios de sua ampla existência na capitania até, pelo menos, a segunda metade do século XVII. Embora o tráfico negreiro já estivesse em franco desenvolvimento e o trabalho dos escravos negros fosse também bastante utilizado, as fontes indicam que os índios ainda constituíam, ali, força de trabalho essencial. Informações documentais e historiográficas permitem supor que, no Rio de Janeiro, tal como na Bahia e em São Paulo, a utilização do trabalho dos escravos africanos aumentava na medida em que diminuíam as possibilidades de uso da mão de obra indígena, por diversas razões que não serão aqui abordadas (Almeida, 2003).

O trabalho dos índios era a alternativa mais racional para uma economia que visava a acumulação com um mínimo de investimentos de capitais. A guerra, principalmente contra o gentio, apresentava-se, na América, como 
mecanismo fundamental de montagem da economia colonial (Fragoso, 1997). Isso se observa claramente no Rio de Janeiro, onde inúmeros povos indígenas aliados ou inimigos desempenharam importante papel, tanto na guerra como na construção e desenvolvimento da nascente capitania. Os inimigos tornavam-se escravos legítimos e eram dados como recompensa aos bravos guerreiros do rei. Ao analisar as formas de acumulação da elite no Rio de Janeiro do século XVII, João Fragoso (1995) demonstrou como a montagem das fortunas das famílias mais poderosas da região não se deu apenas por meio de compras. Seu patrimônio agrário escravista constituiu-se e reproduziu-se também pela doação de sesmarias, índios cativos e crédito, obtidos por estreitas relações com o poder (Fragoso, 1997).

Os aliados também constituíram importante força de trabalho na capitania até o século XIX. Aldeavam-se para cumprir inúmeras funções, dentre as quais a de servir ao rei, aos moradores e aos missionários sob a imposição do trabalho compulsório, regulado por várias leis que, como de praxe, variavam ao longo do tempo e de acordo com a pressão dos interessados. Foram inúmeras as disputas em torno da repartição do trabalho dos aldeados, disputas essas que não se davam simplesmente entre colonos e jesuítas, como costumava sugerir a historiografia. Apesar da condição subalterna e dos incalculáveis prejuízos, abusos e explorações que lhes eram impostos, os índios participaram ativamente dos embates sobre seu trabalho. Os jesuítas, inúmeras vezes, deixaram claro os limites de seu controle sobre eles. A repartição dos aldeados para os serviços ficava a cargo dos líderes indígenas que, como capitães-mores das aldeias, eram encarregados de intermediá-la com o padre superior. As fontes sobre os conflitos nos permitem identificar, nas aldeias, um complexo jogo de forças entre os chefes indígenas, os índios comuns, os padres superiores, os moradores e as autoridades locais. Sem descartar as possíveis dissimulações presentes em todos os discursos que procuravam justificar o não cumprimento das ordens reais, é imperioso constatar a participação dos indígenas nesses embates (Almeida, 2003). Escravizações ilegítimas também foram contestadas pelos próprios índios que recorriam à justiça para obter a liberdade, como demonstraram Mello (2009) na Amazônia e Resende (2003), em Minas Gerais.

Não resta dúvida que a inserção dos índios nas atividades produtivas da capitania passava também por seus próprios interesses e possibilidades de resistência, tendo sido amplamente disputada até o século XIX, tanto no Rio de Janeiro como em outras regiões do Brasil. As atuais pesquisas sobre o trabalho indígena na América portuguesa revelam a complexidade das múltiplas 
formas de relações de trabalho na colônia e apontam para a importância de análises que levam em conta, de forma articulada, as diferentes modalidades de trabalho compulsório e o trabalho escravo de índios, africanos e seus descendentes.

\section{EXTINÇÃO DAS ALDEIAS COLONIAIS E APAGAMENTO DE IDENTIDADES INDÍGENAS: DE MEADOS DO SÉCULO XVIII AO XIX}

A política de Pombal, ponto de inflexão na política indigenista da Coroa, é um tema que tem merecido atenção dos historiadores em diferentes regiões do Brasil e suscitado novas interpretações (Domingues, 2000; Lopes, 2005; Medeiros, 2007; Silva, 2005; Garcia, 2009, entre outros). A nova legislação foi aplicada de diferentes formas, conforme as especificidades locais e as características dos grupos indígenas para os quais se dirigiam, tendo encontrado reações diversas por parte destes últimos. Se muitos resistiram, outros colaboraram e souberam valer-se da lei para assegurar possíveis ganhos. Essas ideias evidenciam-se em pesquisas nas quais a política indigenista de Pombal é analisada de forma articulada às políticas indígenas que contribuíam para delinear seus rumos. Se houve rupturas em relação às políticas anteriores, houve também muitas continuidades, dentre as quais cabe destacar a manutenção dos direitos dos índios aldeados às terras coletivas das aldeias que, em algumas regiões, passaram a ser mais disputadas nesse período.

Foi o caso das antigas aldeias do Rio de Janeiro, nas quais acentuaram-se os conflitos de terra, com a presença cada vez maior de não índios em seu interior que, incentivados pela própria lei, tendiam a expandir-se sobre as terras dos índios, gerando reações. Com o objetivo de transformar as aldeias indígenas em vilas e lugares portugueses e acabar com as distinções entre os índios e os demais súditos do rei, Pombal lançou as bases da proposta assimilacionista, desencadeando o longo processo de extinção das aldeias coloniais que iria se acentuar no decorrer do século XIX, quando a grande maioria delas seria finalmente extinta.

No Rio de Janeiro e em outras regiões, observa-se desde meados do século XVIII, mas principalmente no decorrer do XIX, o acirramento das disputas pelas terras das aldeias, em áreas de colonização antiga. Observa-se também, na documentação sobre esses conflitos, instigantes contradições sobre as classificações étnicas dos aldeados que podiam aparecer ora como índios, ora como mestiços. Com base na ideia de que as categorias étnicas são construídas 
historicamente e adquirem diferentes significados conforme os tempos, os espaços e os agentes sociais, é importante identificar os possíveis interesses dos diferentes atores tanto em classificar como em ser classificado de uma ou de outra forma, tal como pesquisas recentes vêm demonstrando (Almeida, 2008). Trata-se de pensar, como afirmou Boccara, que as disputas por classificações étnicas devem ser vistas como disputas políticas e sociais (Boccara, 2001). Afinal, ser ou não ser índio podia implicar perdas ou ganhos políticos, econômicos e sociais.

Essas disputas, tão evidentes nos estudos sobre etnogênese da atualidade, podem ser identificadas também em conflitos de terra nas aldeias indígenas do passado, desde meados do século XVIII. Os discursos sobre o desaparecimento dos índios que, misturados à massa da população, teriam se tornado mestiços e como tais não teriam mais direito à terra coletiva garantida pela legislação, foram essenciais no processo de extinção das antigas aldeias coloniais. Frequentes por parte de autoridades e colonos interessados em extinguir as aldeias, essas afirmativas eram contrariadas pelas atuações dos aldeados que, considerados poucos, civilizados e misturados à massa da população, seguiam vivendo nas aldeias e reivindicando antigos direitos que lhes eram assegurados pela identidade indígena. De modo geral, foi esse o processo de extinção das antigas aldeias, tanto no Rio de Janeiro como em várias outras regiões do Brasil; processo lento e gradual que se desenvolveu com muitas disputas entre os índios, as câmaras municipais e os moradores (Carneiro da Cunha, 1992; Silva,1996; Almeida, 2008). Eram, fundamentalmente, disputas por terra, nas quais as formas de classificação étnica eram, com frequência, acionadas pelos agentes em confronto. Apresentados como civilizados e extintos, inúmeros índios, ainda aldeados, acabaram perdendo suas terras e aldeias; e muitos, com certeza, assumiram a identidade de caboclos e mestiços na desfavorável conjuntura do século XIX, em que não havia lugar para a pluralidade étnica. Assim, ao invés de terem, de fato, desaparecido, como costumava afirmar a historiografia, os índios das antigas aldeias foram invisibilizados por discursos políticos e intelectuais que, condizentes com a política indigenista do século XIX, visavam assimilá-los, tornando-os produtivos cidadãos do Império brasileiro (Almeida, 2008).

Não é de estranhar, portanto, que vários deles estejam ressurgindo, hoje, por meio dos movimentos de etnogênese da atualidade (Oliveira, 1999). Ao assumirem suas identidades indígenas em busca dos direitos garantidos pela Constituição de 1988, muitos desses grupos buscam suas origens nos antigos aldeamentos extintos no século XIX. A partir dessas atuais leituras sobre as 
trajetórias dos "índios desaparecidos" fica fácil compreender como povos declarados extintos no século XIX tornam-se, hoje, cada vez mais presentes e atuantes no cenário político e acadêmico do país.

\section{Prot AgONISMO INDÍGENA, INTERAÇÕES ÉTNICO-SOCIAIS E RELAÇÕES DE PODER}

Ao demonstrar o protagonismo dos índios na história do Rio de Janeiro, minha pesquisa soma-se às de outros colegas para evidenciar que o domínio colonial português na América não prescindiu de acordos e negociações com os povos indígenas. $\mathrm{O}$ mesmo pode-se afirmar em relação a vários outros atores subalternos, com destaque para os africanos e seus descendentes, tal como os historiadores da escravidão já vêm revelando desde os anos 1980. As interações políticas, sociais e culturais entre índios, africanos e vários outros atores eram intensas e, quando analisadas de forma articulada, propiciam novas compreensões sobre suas próprias escolhas e atuações, bem como sobre os processos históricos nos quais se envolvem, incluindo as relações de poder em diferentes instâncias. Isso tem sido particularmente visível em pesquisas que relacionam índios e africanos.

Sobre isso, vale destacar a reflexão de Sílvia Lara apresentada na abertura do IV Encontro Internacional de História Colonial, em instigante texto no qual demonstra que as relações e acordos com as populações do Novo Mundo foram indispensáveis para a "instalação do domínio português nas terras da América e para a exploração de suas riquezas” (Lara, 2014, p.12). Abordando os complexos e indispensáveis acordos do rei de Portugal com os africanos, (na colônia e na África) e alguns dos mais recentes estudos da história indígena, a autora evidencia a importância do diálogo político entre os agentes da colonização, os africanos e os índios, sem o qual "o domínio colonial não poderia ter se estruturado e se mantido ao longo dos séculos” (Lara, 2014, p.8). E vai além, ao afirmar que esse diálogo deve ser compreendido, levando-se em conta os significados próprios que os atores subalternos atribuíam aos acordos.

Ideia semelhante encontra-se no texto introdutório da Coleção Brasil Colonial, no qual João Fragoso (2014) afirma que a dinâmica da sociedade colonial só se esclarece quando se considera a presença e a atuação dos mais variados agentes, entre os quais inclui "a população que não comungava". Segundo ele, para além dos "europeus, ilhéus dos Açores, da Madeira, africanos, 
muitos mamelucos e índios convertidos", devem-se considerar também "os índios bravos que ocupavam os arredores dos povoados" (Fragoso, 2014, p.10). Ideias como essas afirmadas por dois renomados historiadores, em textos introdutórios para a apresentação dos debates e trabalhos de conceituados especialistas de nossa história colonial, são significativas quanto à importância de valorizar o protagonismo de atores que por tanto tempo foram negligenciados em nossa historiografia.

Duas questões mencionadas por eles já vêm sendo abordadas de forma articulada e complexa, pela história indígena e pela história da escravidão, propiciando novas leituras sobre as relações de poder na colônia. Refiro-me à inclusão dos índios bravos como sujeitos históricos, destacada por Fragoso, e à necessidade de reconhecer os interesses políticos dos vários povos envolvidos nos acordos estabelecidos com os portugueses, apontada por Lara. As variadas motivações que impulsionavam índios (aldeados e selvagens) e negros (africanos, crioulos, escravos, livres e forros) a estabelecer múltiplas e inconstantes relações de aliança e conflito entre si e com outros agentes têm sido identificadas por inúmeras pesquisas interdisciplinares que buscam desvendar os significados próprios que eles atribuíam aos acordos realizados. Para isso, lançam mão do conceito de cultura política (Bernstein, 1998), considerando seus próprios códigos culturais, suas percepções, suas lógicas cognitivas e suas vivências construídas e modificadas na dinâmica de suas interações. Os índios bravos também têm merecido mais atenção dos historiadores, sobretudo nas regiões de fronteira, repensadas a partir das interações entre eles e os demais atores, tanto na colônia quanto no Império brasileiro (Kok, 2004; Langfur, 2002; Sena, 2013; Amantino, 2008; Resende, 2003).

Reafirmo, portanto, a importância das relações interétnicas e sociais entre os subordinados que, além de lhes darem importante referencial de identificação, como afirmou Schwartz (1996), exerciam considerável influência sobre suas decisões e possibilidades de negociação entre eles próprios e com os agentes do poder. Afinal, as funções de defesa na colônia eram essenciais para a Coroa, e o temor aos rebeldes, fossem eles índios bravos, quilombolas ou escravos fugitivos, levava autoridades a fazer concessões aos demais subalternos que os combatiam. Estes, por sua vez, sabiam aproveitar as oportunidades de negociar. Autoridades, senhores e índios (aldeados e selvagens) uniam-se na perseguição aos quilombolas e aos escravos fugitivos, tal como os escravos negros associavam-se às autoridades e senhores para lutar contra os chamados "selvagens" (Moreira, 2010). Estes últimos também negociavam com colonos e autoridades, pois entravam e saíam das sociedades envolventes, interagindo 
com os demais atores e passando, por vezes, de uma categoria a outra. Ao analisar de forma conjunta índios aldeados, índios selvagens, quilombolas, fugitivos, degredados, missionários e autoridades locais e distantes, buscando identificar os interesses variados que os impulsionavam, vários estudos localizados complexificam as redes de relações sociopolíticas localmente engendradas e demonstram como seus efeitos repercutiam em esferas políticas muito mais amplas, tanto na colônia quanto na Metrópole (Amantino, 2008; Gomes, 2005; Schwartz; Langfur, 2003; Garcia, 2009).

Fundamentais para essas análises são as atuais tendências teóricas e conceituais da História Política que, incorporando as ideias de pacto, negociação e cultura política, complexificam as relações de poder, não só entre a metrópole e a colônia, como também entre os diversos agentes e instituições das várias instâncias político-administrativas dos dois lados do Atlântico. As ideias dicotômicas que presidiam estudos sobre as relações de poder entre colônias e metrópoles, bem como entre os chamados dominantes e dominados, dão lugar a concepções mais complexas que valorizam as dinâmicas internas das sociedades coloniais, incluindo as agências dos mais diversos atores (Gouvêa, 2005; Fragoso, 2014). A construção das leis e suas variadas formas e possibilidades de aplicação e uso para os diferentes agentes sociais são outro tema que tem se renovado sob novas perspectivas de análise. Compreendidas como resultantes de negociações e confrontos entre os agentes interessados e suas respectivas capacidades de fazer valer seus interesses, elas deixam de ser vistas unicamente como instrumentos de legitimação de relações desiguais. Para além de propiciarem ganhos aos mais poderosos, elas comportam possibilidades de mediação através de brechas que permitem reivindicações dos menos favorecidos (Thompson, 1987).

Os inúmeros estudos sobre as múltiplas formas de atuação dos indígenas, africanos e seus descendentes na colônia em defesa de seus interesses ancoram-se nessas concepções e, ao mesmo tempo, contribuem para reforçá-las. Analisar todos esses grupos de forma conjunta nos permite, portanto, perceber como suas ações de aliança ou rebeldia com os poderes constituídos propiciavam, a uns e outros, maiores ou menores possibilidades de negociação. Desafios, pressões e acordos exercidos pelos subalternos influenciavam decisões dos agentes de diferentes instâncias do poder (civil e eclesiástico, local e metropolitano) e as próprias leis que se construíam, se adaptavam ou se anulavam, conforme pressões e circunstâncias. Deduz-se daí a importância de estudar suas trajetórias, atuações, interesses e escolhas de forma articulada para uma compreensão mais ampla e complexa sobre as relações de poder na colônia. 


\section{CONSIDERAÇÕES FINAIS}

Lembrando que os avanços historiográficos nos vários campos de saber caminham juntos e influenciam-se mutuamente, convém considerar que a história indígena, beneficiada pelo desenvolvimento de pesquisas em outras áreas, renova-se continuamente, produzindo conhecimentos que possibilitam repensar vários outros temas, como procurei demonstrar ao longo deste artigo. Porém, retomando as considerações de Monteiro (1995) e Lara (2014), vale ressaltar que ainda temos muito que avançar, sobretudo, no sentido de conectar histórias, pois ainda são poucos os historiadores que, voltados para outros temas, incorporam as contribuições da história indígena e da história da escravidão para repensar seus próprios objetos de análise. Quando essa prática se tornar mais frequente, não tenho dúvida de que muitas outras revisões historiográficas serão feitas. Muitas outras páginas da nossa história serão reescritas e os índios poderão, talvez, ter um futuro melhor (Monteiro, 1995).

Esta última observação de Monteiro aponta para o fato de que, para além da contribuição acadêmica aqui apresentada, a inclusão dos índios como protagonistas em nossa história reveste-se também de extrema importância do ponto de vista social e político. Ao revelarem as atuações dos índios na História do Brasil, restituindo-lhes a condição de sujeitos, as novas interpretações são essenciais para desconstruir ideias preconceituosas e racistas ainda muito presentes em nossas sociedades, sobretudo em regiões próximas às áreas indígenas. Para os índios, em especial, as novas narrativas têm o efeito de fortalecer sua autoestima, na medida em que se veem representados como agentes de suas próprias histórias. Histórias de imensas perdas, derrotas, mortes, explorações e deslocamentos forçados, porém histórias também suas, nas quais não deixaram de atuar, nem tampouco se anularam, enquanto grupos distintos.

Além disso, o conhecimento do passado e de suas próprias trajetórias é um relevante instrumento de luta para os povos indígenas que, desde o período colonial, têm lançado mão desse recurso para reafirmarem seus direitos. Não à toa, muito deles estão entrando nas universidades e escrevendo suas próprias histórias. Para os não índios, por sua vez, as novas compreensões sobre as complexas e diferenciadas trajetórias dos índios na história do Brasil podem ter duplo efeito. Além de levá-los a abandonar preconceitos e discriminações alimentados por tantas ideias equivocadas, podem também fornecer-lhes elementos para que reconheçam os legítimos direitos dos índios, levando-os, quem sabe, a substituir discursos de oposição e violência pelo apoio às suas causas. 
Se pensarmos quantas gerações foram educadas com base em ideias negativas e preconceituosas em relação a povos indígenas, povos que agora reivindicam terras, culturas e direitos próprios garantidos pela Constituição de 1988, podemos ter uma ideia do tamanho do prejuízo, do quanto há para reparar e da importância dessa revisão historiográfica de que nos falava Monteiro em 1995. Reescrever a história do Brasil incorporando os indígenas e vários outros povos, como os africanos e seus descendentes, na condição de sujeitos históricos, é, reafirmo, de fundamental importância do ponto de vista acadêmico, social e político.

\section{REFERÊNCIAS}

ALMEIDA, M. Regina Celestino de. Índios e mestiços no Rio de Janeiro: significados plurais e cambiantes. Memoria Americana, Buenos Aires: Instituto de Ciências Antropológicas, n.16, p.19-40, 2008. . Os índios na História do Brasil. Rio de Janeiro: Ed. FGV, 2010.

. Metamorfoses indígenas: identidade e cultura nas aldeias coloniais do Rio de Janeiro. Rio de Janeiro: Arquivo Nacional, 2003.

AMANTINO, Márcia. O mundo das feras: os moradores dos sertões oeste de Minas Gerais - século XVIII. São Paulo: Annablume, 2008.

BARBOSA, Bartira. Paranambuco: poder e herança indígena - Nordeste, séculos XVI-XVII. Recife: Ed. Universitária da UFPE, 2007.

BARTH, Fredrick. Os grupos étnicos e suas fronteiras. In: LASK, Tomke (Ed.) O guru, $o$ iniciador e outras variações antropológicas. Trad. John Cunha Comerford. Rio de Janeiro: Contra Capa, 2000. p.25-67.

BERNSTEIN, Serge. A cultura política. In: RIOUX, Jean-Pierre; SIRINELLI, Jean-François (Ed.) Para uma história cultural. Lisboa: Estampa, 1998. p.349-363.

BOCCARA, Guillaume. Mundos nuevos en las fronteras del Nuevo Mundo. Nuevo Mundo Mundos Nuevos, revista eletrônica, Paris: École des Hautes Études en Sciences Sociales, 2001. Disponível em: http://nuevomundo.revues.org/426; Acesso em: 17 set. 2012.

CARDOSO, Ciro F.; VAINFAS, Ronaldo (Ed.) Domínios da História: ensaios de teoria e metodologia. Rio de Janeiro: Campus, 1997.

.; VAINFAS, Ronaldo (Ed.) Novos Domínios da História. Rio de Janeiro: Campus, 2012.

CARNEIRO DA CUNHA, Manuela. Introdução a uma história indígena. In:

(Ed.) História dos Índios no Brasil. São Paulo: Companhia das Letras, 1992. p.9-24.

CARVALHO JÚNIOR, Almir Diniz de. Índios cristãos: poder, magia e religião na Amazônia colonial. Curitiba: Ed. CRV, 2017. (no prelo). 
CASTELNAU-L'ESTOILE, Charlotte de. Operários de uma vinha estéril: os jesuítas e a conversão dos índios no Brasil - 1580-1620. Trad. Ilka Stern Cohen. Bauru, SP: Edusc, 2006.

DOMINGUES, Ângela. Quando os índios eram vassalos: colonização e relações de poder no Norte do Brasil na segunda metade do século XVIII. Lisboa: CNCDP, 2000.

FAUSTO, Carlos. Os índios antes do Brasil. Rio de Janeiro: Jorge Zahar, 2000.

FRAGOSO, João. Apresentação. In: .; GOUVÊA, Maria de Fátima (Ed.) O Brasil Colonial 1443-1580. Rio de Janeiro: Civilização Brasileira, 2014. p.7-37. Cartas que falam sobre a pintura do arquiteto do mundo. (Introdução). Documentos Históricos, Rio de Janeiro: Biblioteca Nacional, v.CXI, 1997. p.15-24).

. À espera das frotas: hierarquia social e formas de acumulação no Rio de Janeiro, século XVII. Cadernos do Laboratório Interdisciplinar de Pesquisa em História Social, Rio de Janeiro: IFCS/UFRJ, n.1, p.53-62, 1995.

FERNANDES, Florestan. A organização social dos Tupinambá [1949]. São Paulo: Hucitec, 1989.

GARCIA, Elisa Frühauf. As diversas formas de ser indio: políticas indígenas e políticas indigenistas no extremo sul da América portuguesa. Rio de Janeiro: Arquivo Nacional, 2009.

GODOY, Silvana Alves de. Mestiçagem, guerras de conquista e governo dos índios: a vila de São Paulo na construção da Monarquia Portuguesa na América (séculos XVI e XVII). Tese (Doutorado em História) - Universidade Federal do Rio de Janeiro (UFRJ). Rio de Janeiro, 2017.

GOMES, Flávio dos Santos. A hydra e os pântanos: mocambos, quilombos e comunidades de fugitivos no Brasil (séculos XVII-XIX). São Paulo: Ed. Unesp, 2005.

GOUVÊA, M. de Fátima S. Diálogos historiográficos e cultura política na formação da América Ibérica. In: SOIHET, Rachel; BICALHO, M. Fernanda B.; GOUVÊA, M. de Fátima S. (Ed.) Culturas políticas: ensaios de história cultural, história política e ensino de história. Rio de Janeiro: Mauad, 2005.

GUIMARÃES, Manoel Luiz S. Nação e civilização nos Trópicos: o Instituto Histórico e Geográfico Brasileiro e o projeto de uma História Nacional. Estudos Históricos, Rio de Janeiro: CPDOC/FGV, n.1, p.5-27, 1988.

HEMMING, John. Ouro vermelho: a conquista dos índios brasileiros. Trad. Carlos Eugênio Marcondes de Moura. São Paulo: Edusp, 2007.

HILL, Jonathan (Org.) History, Power and Identity: ethnogenesis in the Americas, 19421992. Iowa City: University of Iowa Press, 1996.

KODAMA, Kaori. Os índios no Império do Brasil: a etnografia do IHGB entre as décadas de 1840 e 1860. Rio de Janeiro: Ed. Fiocruz; São Paulo: Edusp, 2009.

KOK, Gloria. O sertão itinerante: expedições da Capitania de São Paulo no século XVIII. São Paulo: Hucitec; Fapesp, 2004. 
LANGFUR, Hal. Uncertain Refuge: Frontier formation and the origins of the Botocudo War in late colonial Brazil. Hispanic American Historical Review, v.82, n.2, p.215-256, 2002.

LARA, Silvia Hunold. O Domínio Colonial e as Populações do Novo Mundo. In: ENCONTRO INTERNACIONAL DE HISTÓRIA COLONIAL, IV., 2012, Belém. Anais... Belém: Açaí, 2014. v.1, p.1-14.

LOPES, Fátima Martins. Em nome da liberdade: as vilas de índios do Rio Grande do Norte sob o Diretório Pombalino no século XVIII. Tese (Doutorado em História) - Universidade Federal de Pernambuco (UFPE). Recife, 2005.

MARCHANT, Alexander. Do escambo à escravidão. Trad. Carlos Lacerda. 2.ed. São Paulo: Cia. Ed. Nacional; [Brasília]: INL, 1980.

MEDEIROS, Ricardo Pinto de. Política indigenista e seus reflexos nas Capitanias do Norte da América portuguesa. In: .; OLIVEIRA, Carla Mary S. (Ed.) Novos olhares sobre as Capitanias do Norte do Estado do Brasil. João Pessoa: Ed. Universitária UFPB, 2007. p.125-159.

MELLO, Evaldo Cabral de. O nome e o sangue: uma fraude genealógica no Pernambuco Colonial. São Paulo: Companhia das Letras, 1989.

MELLO, Marcia Eliane A. S. Fé e Império: as Juntas das Missões nas conquistas portuguesas. Manaus: Ed. Ufam, 2009.

MINTZ, Sidney W. Cultura: uma visão antropológica. Trad. James Emanuel de Albuquerque. Tempo, Niterói: Eduff, v.14, n.28, p.223-237, 2010.

MONTEIRO, John Manuel. O desafio da História Indígena no Brasil. In: SILVA, Aracy Lopes da S.; GRUPIONI, Luís D. Benzi (Ed.) A temática indígena na escola: novos subsídios para professores de $1^{\circ}$ e $2^{\circ}$ graus. Brasília: MEC; Mari; Unesco, 1995. p.221-228.

. Negros da terra: índios e bandeirantes - origens de São Paulo. São Paulo: Companhia das Letras, 1994.

. Tupis, tapuias e historiadores: estudos de História Indígena e do indigenismo. Tese (Livre Docência em História) - Universidade Estadual de Campinas (Unicamp). Campinas, 2001.

MOREIRA, Vânia Maria L. Entre índios e escravos armados: alianças interétnicas e formação de quilombos na província do Espírito Santo, 1808-1850. Afro-Ásia, Salvador, n.41, p.57-83, 2010.

OLIVEIRA, João Pacheco de (Org.) A viagem da volta: etnicidade, política e reelaboração cultural no Nordeste indígena. Rio de Janeiro: Contra Capa, 1999.

PERRONE-MOISÉS, Beatriz. Índios livres e índios escravos: os princípios da legislação indigenista do período colonial (séculos XVI a XVIII). In: CARNEIRO DA CUNHA, Manuela. História dos Índios no Brasil. São Paulo: Companhia das Letras, 1992. p.115-132.

POMPA, Cristina. Religião como tradução: missionários, Tupi e "tapuia" no Brasil Colonial. Bauru, SP: Edusc, 2003. 
RAMINELLI, Ronald. Nobrezas do Novo Mundo: Brasil e Ultramar Hispânico, séculos XVII e XVIII. Rio de Janeiro: Ed. FGV, 2015.

RESENDE, M. Leônia Chaves de. Gentios brasílicos: índios coloniais em Minas Gerais setecentista. Tese (Doutorado em História) - Universidade Estadual de Campinas (Unicamp). Campinas, 2003.

ROCHA, Rafael Ale. A elite militar no estado do Maranhão: poder, hierarquia e comunidades indígenas (século XVII). Tese (Doutorado em História) - Universidade Federal Fluminense (UFF). Niterói, 2013.

SCHWARTZ, Stuart. Brazilian Ethnogenesis: Mestiços, Mamelucos, and Pardos. In: GRUZINSKI, Serge; WACHTEL, Nathan (Ed.) Le Nouveau Monde: Mondes nouveaux. L'experience americaine. Paris, 1996. p.7-27.

. Segredos internos: engenhos e escravos na sociedade colonial. Trad. Laura Teixeira Motta. São Paulo: Companhia das Letras, 1988.

.; LANGFUR, Hal. Tapanhuns, negros da terra e curibocas: causas comuns e confrontos entre negros e indígenas. Afro-Ásia, Salvador, v.29/30, p.13-40, 2003.

SENA, Ernesto Cerveira de. Disputas, integraciones y transgresiones en la región de frontera: márgenes de Bolívia e Imperio de Brasil (1825-1850). Saarbrücken: Dictus Publishing, 2013.

SILVA, Edson. Confundidos com a massa da População: o esbulho das terras indígenas no Nordeste no século XIX. Revista do Arquivo Público de Pernambuco, Recife, v.42, n.46, p.17-29, 1996.

SILVA, Isabelle B. Peixoto da. Vilas de índios no Ceará Grande: dinâmicas locais sob o Diretório Pombalino. Campinas: Pontes, 2005.

THOMPSON, Edward P. Miséria da teoria. Trad. Waltensir Dutra. Rio de Janeiro: Zahar, 1981.

Senhores e caçadores. Trad. Denise Bottman. Rio de Janeiro: Paz e Terra, 1987.

VAINFAS, Ronaldo. A heresia dos índios: catolicismo e rebeldia no Brasil Colonial. São Paulo: Companhia das Letras, 1995.

VIVEIROS DE CASTRO, Eduardo. O mármore e a murta: sobre a inconstância da alma selvagem. Revista de Antropologia, São Paulo: USP, v.35, p.21-74, 1992.

\section{NOTA}

${ }^{1}$ Agradeço ao CNPq o apoio à pesquisa mediante bolsa de produtividade PQ.

Artigo recebido em 17 de fevereiro de 2017. Aprovado em 27 de março de 2017. 